\title{
ПРОБЛЕМАТИКА СОБЫТИЙНОСТИ ДЕТСТВА В ЗАРУБЕЖНЫХ ЖУРНАЛАХ *
}

\author{
(c) 2018 Митрофанова Светлана Юрьевна \\ кандидат социологических наук, доцент кафедры социологии и культурологии \\ Самарский национальный исследовательский университет им. Академика С.П. Королева \\ 443086, г. Самара, ул. Московское шоссе, д. 34 \\ E-mail:mit_s@mail.ru
}

В статье поднимается тема событийности детства. На примере аннотаций и названий статей трех зарубежных журналов по детству: «Детство: глобальный журнал исследований ребенка», «Глобальные исследования детства», «География детей» - доказывается, что в современном обществе происходят сдвиги в «нормативных» образах детства, представлениях о событийности детства, обосновывается идея многовекторности и множественности моделей детско-взрослых отношений и взросления детей.

\section{Ключевые слова: событийность детства, зарубежные журналы по детству}

Детство отличается постоянной ориентацией на взрослый мир. События жизни ребенка закладывают фундамент развития его личности, оказывают серьезное влияние на дальнейшую жизнь. По этой логике, в условиях, когда взрослая культура защищает границы детства, событийность последнего должна выстраиваться с учетом постепенного и поэтапного освоения социальности, ориентирующей на сообщество взрослых. Однако, ряд авторов говорят о трансформации социальности в глобализирующемся мире, ее ограничении, сокращении, о том, что взрослая культура в современном обществе перестает держать границы детства, о наступившем кризисе детства, понимая последний как кризис событийности детско-родительских отношений [например, 1]. На примере статей зарубежных журналов, содержащих данные авторских эмпирических исследований детей, обозначим, как в них вписана проблематика событийности детства, и дадим ответ на вопрос о том, подкрепляют ли результаты этих исследований по событийности детства идею однонаправленность взросления, или указывают на многовекторность и множественность моделей детско-взрослых отношений и взросления детей.

Данный вопрос рассмотрим на основе обращения исследовательского внимания к названию и аннотациям статей таких зарубежных журналов по детству, как «Детство: глобальный журнал исследований ребенка» (Childhood. A journal of global child research) и «Глобальные исследования детства» (Global Studies of Childhood) издательства Sagepub, «География детей» (Children's Geographies) издательства Routledge. Выбор данных журналов обусловлен тем, что в них содержится достаточно широкий, междисциплинарный взгляд на детство в отличие от журналов более узкой направленности, например, с такими названиями как: «Современные вопросы раннего детства» (Contemporary Issues in Early Childhood), «Нетипичные дети», (Exceptional Children), «Журнал одаренного ребенка» (Gifted Child Quarterly) и другие. Интерес к выше обозначенным журналам также обусловлен наличием в открытом доступе всех аннотаций и даже отдельных полных текстов статей.

Вопросы событийности детства так или иначе вписаны в такие проблематики исследований зарубежных авторов, как: изучение транзиции от детства к зрелости, концепта заботы в отношениях между родителями и детьми, выстраивания ребенком своей идентичности через трудовую деятельность, гендерных измерений тех или иных аспектов жизни детей и т.д.

Отметим, что проведенный нами анализ событийности детства [например, 2; 3] свидетельствует о том, что взрослая культура в современном обществе перестает держать границы детства, и само понятие детства (как и других концептов, связанных с взрослением человека) становится более расплывчатым, прерывистым,

\footnotetext{
* Статья, написана при поддержке гранта РГНФ (грант № 16-06-00792а, Детство в социогуманитарной перспективе: тезаурус 2016-2018).

This article was prepared with the support of the Russian Humanitarian Scientific Fund (grant No. 16-06-00792a, Childhood in the socio-humanistic perspective: the thesaurus 2016-2018).
} 
нечетким, аморфным. На наш взгляд, этот тезис подтверждают и результаты исследований проведенных зарубежными авторами отдельных событий жизни детей, таких как переживание детьми развода родителей, трудовая деятельность, употребление алкоголя и другие.

Анализ переживания детьми развода родителей связан с трактовкой концепта «заботы» в детско-родительских отношениях. Его традиционное толкование основано на том, что родители дают заботу детям, а дети получают ее от них. Однако, как указывает Anja Marschall, на основе исследования повседневной жизни датских детей 8-12 лет и их родителей после развода, забота - это не однонаправленный, а взаимный процесс поддержки и ухода детей и родителей друг за другом [4].

О неоднозначности интерпретаций событий детства, размывании его содержания, свидетельствуют исследования детского труда, зависимости последнего от социально-экономического класса, к которому принадлежат родители детей, территории их проживания, занятости родителей и ряда других факторов. Так, Géraldine André и Marie Godin указывают на различные трактовки детского труда, связанного с добычей полезных ископаемых в Демократической Республике Конго (ДРК). В ДРК в течение последних трех десятилетий расширяется развитие кустарной и мелкомасштабной горнодобывающей промышленности, в результате чего в этот процветающий деловой сектор приходит все больше городских семей, в том числе детей. Авторы подчеркивают, что в соответствии с международным законодательством о правах ребенка этот вид занятости детей относится к одной из наихудших форм детского труда. Показано, что для семей из среднего класса этот вид работы зачастую является социально деструктивным, находящимся в авангарде межпоколенческого конфликта. Что касается семей из низших классов, то социальные изменения, вызванные деятельностью детей в горнодобывающей промышленности, лучше вписаны в их габитус [5].

Enoch Tawiah Sackey и Berit Overå Johannesen исследуют значения, которые дети, вовлеченные в рыболовство и фермерство в двух общинах г. Кейп-Кост (Гана, Африка), придают своему участию в работе и школе. Авторы отмечают, что дети рассказывают о том, как они выстраивают свою идентичность, приобретают уважение и компетентность через работу, описывая соб- ственные усилия как воспроизводство традиционного межпоколенческого порядка с сильными нравственными коннотациями. Но вместе с тем, в будущем многие из них мечтают о других видах занятости [6]. Таким образом, практики вовлечения в трудовую деятельность детей как компонент событийности их детства находят различное отражение как в собственных пониманиях детьми значений этой деятельности, так и трактовках их родителей.

Первая проба алкоголя - один из компонентов событийности детства. Clare Holdsworth, Louise Laverty и Jude Robinson рассматривают гендерные различия в алкогольном поведении мальчиков и девочек 13-14 лет в контексте пространства в Ливерпуле, Великобритания [7]. Ученые исследуют, как использование пространства было связано с экспериментами с алкоголем, каков гендерный аспект опыта употребления алкоголя. Gill Valentine, Mark Jayne и Myles Gould отмечают, что средний возраст начала употребления спиртных напитков в Европе сегодня - 12 лет. Авторы проводят эмпирическое исследование роли алкоголя в семейной жизни Великобритании, изучая, в частности, информированность детей об алкоголе, их понимание рисков для здоровья, связанных с употреблением алкоголя [8].

Приобретение способности нести ответственность по уходу за домашним животным также можно рассматривать как важный компонент событийности детства. Janine C. Muldoon, Joanne M. Williams, Alistair Lawrence отмечают, что отношения с конкретными животными часто рассматриваются как «мостик» к заботе об окружающей среде в целом. Авторы статьи методом фокус-группы с детьми в возрасте от 7 до 13 лет изучили их деятельность, формирование чувства ответственности в процессе ухода за домашними животными, влияние на детей родительских ролей и ограничений, связанных с заботой детей о своих питомцах [9].

Сексуальность детей также можно рассматривать с точки зрения компонентов событийности детства. Проблематике детской сексуальности посвящены статьи Ingrid Voléry и Deevia Bhana. Ingrid Voléry концентрируется на исследовании форм сексуализации детей, построенных французскими властями в период с 2000 по 2013 год [10]. Deevia Bhana анализирует, как южноафриканские индийские подростки - мальчики и девочки концептуализируют желание, секс и 
любовь. В статье обращается внимание на переосмысление детства, распространение детской активности за пределы озабоченности сексуальной опасностью. Фокусируясь на разнообразии сексуальных значений, внимание уделяется множественности детского сексуального опыта среди южноафриканских индийских подростков. В статье утверждается, что более глубокое понимание подросткового удовольствия и власти может заострить внимание на интервенциях, способствующих здоровой подростковой сексуальности [11]. Данные представленных исследований свидетельствуют о наличии различных режимов детской сексуальности как способов организации последней. Определенные режимы конструируются как внешними структурами (территория проживания, традиции, законодательство, принадлежность к социально-экономическому классу, этнической группе и т.д.), так и воссоздаются сексуальными практиками самих детей.

Образование выступает важным элементом событийности детства, этой тематике посвящены статьи Lydia Marshall [12], Maria Hatzigianni [13]. Обсуждаются вопросы значения образования для детей, использования информационных технологий на разных ступенях образовательного процесса, в том числе и дошкольного. Сам доступ детей к цифровым технологиям также является важным компонентом событийности детства [14].

Организованный досуг выступает компонентом событийности детства. Susanne Nordbakke исследовала досуг вне дома детей 6-12 лет в
2005 и 2013-2014 годах в Норвегии. Автор отмечает, что доля детей, участвующих в организованном досуге, увеличилась, что они начинают участвовать в нем в более раннем возрасте и что интенсивность участия в организованном досуге возросла [15].

О трансформации семейной социализации ребенка свидетельствуют результаты проведенного Anna Malmquist, Anna Möllerstrand, Maria Wikström, Karin Zetterqvist Nelson исследования детей в семьях лесбиянок: представлений детей об идентичности их родителей [16].

Отметим специфику публикаций журнала Childhood, в нем огромное внимание уделяется исследованию «нетипичных» детей. Так, в качестве объектов эмпирических исследований выступают дети с ограниченными возможностями, в том числе умственными. Исследуется, в частности, специфика участвующих исследований с ними, в том числе тех, что посвящены проблематике сексуальности, их праву на образование и т.Д.. Дети мигрантов, дети в странах третьего мира, дети в семьях с низким уровнем доходов, дети этнических меньшинств (например, цыгане) и другие подобные категории детей выступают объектом исследовательского интереса.

Таким образом, исследовательский фокус на обозначенных проблематике и категориях исследуемых детей указывают на сдвиги в «нормативных» образах детства и представлениях о событийности детства, что также подтверждают результаты исследований отечественных авторов, упомянутых в данной статье.

\section{Библиографический список}

1. Эльконин Б.Д. Кризис детства и основания проектирования форм детского развития [Электронный ресурс] // Вопросы психологии. 1992. № 3. C.7-13. http://www.voppsy.ru/issues/1992/923/923007.htm (дата обращения: 1 октября 2018)

2. Майорова-Щеглова С.Н. Влияние событийности детства поколения Z на социопсихологические проблемы студенческой жизни: реперные точки психологической службы вуза / Психологическая служба университета: реальность и перспективы. Материалы I Всероссийской научно-практической конференции с международным участием. 2017. С. 266-271.

3. Митрофанова С.Ю. Маркеры «взрослости» и события детства / Географии детства: междисциплинарный синтез исследовательских подходов и практик. Материалы международной молодежной научной школы-конференции. Ответственный редактор А.Г. Филипова. 2018. С. 159-162.

4. Marschall A. Who cares for whom? Revisiting the concept of care in the everyday life of post-divorce families // Childhood. 2014. Vol.21. Is.4. Pp. 517-531.

5. André G., Godin M. Child labour, agency and family dynamics. The case of mining in Katanga (DRC) // Childhood. 2014. Vol.21. Is.2. Pp. 161-174.

6. Sackey E. T., Johannesen B.O. Earning identity and respect through work: A study of children involved in fishing and farming practices in Cape Coast, Ghana // Childhood. 2015. Vol.22. Is.4. Pp. 119-133. 
7. Holdsworth C., Laverty L., Robinson J. Gender differences in teenage alcohol consumption and spatial practices // Children's Geographies. 2017. Vol. 15. Is. 6. Pp.741-753.

8. Gill V., Jayne M., Gould M. The proximity effect: The role of the affective space of family life in shaping children's knowledge about alcohol and its social and health implications // Childhood. 2014. Vol.21. Is.2. Pp. 103-118.

9. Muldoon J. C., Williams J.M., Lawrence A. «Mum cleaned it and I just played with it»: Children's perceptions of their roles and responsibilities in the care of family pets // Childhood. 2015. Vol.22. Is.2. Pp. 201-216.

10. Voléry I. Sexualisation and the transition from childhood to adulthood in France: From age-related child development control to the construction of civilisational divides // Childhood. 2016. Vol.23. Is.1. Pp. 143-153.

11. Bhana D. Sex isn't better than love': Exploring South African Indian teenage male and female desires beyond danger // Childhood. 2016. Vol.23. Is.3. Pp. 362-377.

12. Marshall L. 'Going to school to become good people': Examining aspirations to respectability and goodness among schoolchildren in urban Ethiopia // Childhood. 2016 Vol.23. Is.3. Pp. 423-437.

13. Hatzigianni M. Transforming early childhood experiences with digital technologies // Global Studies of Childhood. 2018. Vol.8. Is.2. Pp. 173-183/

14. Dias P., Brito R., Ribbens W. The role of parents in the engagement of young children with digital technologies: Exploring tensions between rights of access and protection, from 'Gatekeepers' to 'Scaffolders' // Global Studies of Childhood. 2016. Vol.6. Is.4. Pp. 414-427.

15. Nordbakke S. Children's out-of-home leisure activities: changes during the last decade in Norway // Children's Geographies. 2018 https://twitter.com/childrensgeogs (дата обращения: 1 октября 2018).

16. Malmquist A., Möllerstrand A., Wikström M., Nelson K.Z. A daddy is the same as a mummy: Swedish children in lesbian households talk about fathers and donors // Childhood. 2014. Vol.21. Is.1. Pp. 119-133.

Поступила в редакцию 09.10.2018 